\title{
A ideia da formação (universitária) e sua deformação econômica: um cântico final ${ }^{1}$
}

Dirk Stederoth $^{*}$

\section{Resumo}

O artigo procura fazer um breve balanço da situação universitária alemã, tomando como referência os efeitos produzidos pela introdução das medidas e exigências oriundas da Declaração de Bolonha. Primeiro expõe e analisa cada uma das seis principais medidas da Declaração. Na sequência, indica as consequências visíveis que ela provoca, do ponto de vista pedagógico e intelectual, na formação dos estudantes, dedicando-se, também, a analisar, brevemente, seus efeitos na educação primária e secundária. Por fim, com o intuito de realizar um balanço crítico da situação, recorre ao sentido clássico da formação alemã (Bildung), destacando três de seus muitos aspectos. No bojo da discussão, encontra-se o esforço em empreender a crítica à tendência mundial, e especialmente alemã, de economicização da educação.

Palavras-chave: Autonomia. Bildung. Economicização da Educação. Educação Superior. Liberdade.

\section{Introdução}

Trago, neste artigo, uma pequena contribuição, na qual tratarei de tendências atuais no sistema alemão de formação e, mais especificamente, no campo universitário; tendências essas que, assim presumo, não devem estar muito longe daquelas vividas aqui no Brasil. A tese básica de minhas breves considerações consiste no fato de que os problemas atuais das escolas superiores alemãs (diante da situação atual, prefiro não falar mais de "universidades") não têm a ver apenas com as reformas estruturais que, há mais de dez anos, vêm unificando, sob o título de "Processo de Bolonha”, o espaço universitário europeu. Tais problemas expressam muito mais uma economização crescente dos sistemas de formação em todos os níveis. O título

Recebido em 22 de novembro de 2012. Aprovado em 10 de fevereiro de 2013.

http://dx.doi.org/10.5335/rep.2013.3514

Possui graduação, mestrado, doutorado e livre-docência em Filosofia pela Universidade de Kassel, Alemanha. E-mail: d.stederoth@uni-kassel.de. 
muito geral da "economização" pode ser precisado aí, como redução considerável da formação à instrução profissional, caracterizada tanto pelo aproveitamento geral de bens de formação quanto por objetivos determinados por critérios de efetividade. A formação, no sentido de instrução profissional, perdeu o status de fim em si mesma, apresentando-se, agora, como caminho operacional para alcançar objetivos prescritos pelo mercado de trabalho. Isso obriga a estrutura das instituições a cumprir tais objetivos.

Em seguida, quero fundamentar minha tese em três passos: primeiro, exporei as reformas estruturais das escolas superiores e suas consequências. Farei, depois disso, um pequeno excurso sobre as tendências análogas nas outras instituições educativas, para, finalmente, avaliar esse panorama, tomando como referência normativa a ideia clássica de formação.

"Europe is not onlythat of the Euro, of the banks and the economy: it must be a Europe of knowledge as well" - eis o credo da Declaração de Sorbonne, de maio de 1998, que marca o início do assim chamado Processo de Bolonha. Quão intimamente, porém, a Europa do Euro e da economia está vinculada à Europa do saber já se mostra quando olharmos para as demandas principais da Declaração de Bolonha, assinada em 1999 por 29 estados europeus. Essas seis demandas principais são as seguintes:

1) "introdução de um sistema de exames de entendimento fácil e comparável";

2) "introdução de um sistema baseado, essencialmente, em dois ciclos principais (a estrutura ungraduate-graduate, respectivamente, Bachelor-Master)";

3) "introdução de um sistema de créditos - semelhante ao ECTS (isto é, European-Credit-Transfer-System) - como instrumento adequado para promover a máxima mobilidade dos estudantes";

4) "promoção da mobilidade através da superação de entraves que dificultam, na prática, a liberdade de residência";

5) "promoção da cooperação europeia quanto à garantia de qualidade, mediante a elaboração de critérios e métodos comparáveis";

6) "promoção das necessárias dimensões europeias no campo das instituições superiores (desenvolvimento de currículos; programas integradores de estudo e de pesquisa; etc.)" ${ }^{3}$

No centro dessas demandas, consta a tendência em direção à unificação, respectivamente, à comparabilidade, no intuito de chegar à contabilização mais 
abrangente possível dos processos de formação. Gostaria de analisar, individualmente, cada uma dessas demandas.

As primeiras duas demandas que, na verdade, são interconectadas, visam a normatizar, em nível europeu, os exames universitários finais; algo que, na prática, levou a um currículo do Bachelor, de seis semestres, e do Master, de quatro semestres. Deveriam ser revogados, assim, tipos específicos de exames finais, tais como, na Alemanha, o diploma ou a licenciatura, com o objetivo de fazer valer critérios de avaliação unificados no mercado de trabalho europeu. Entretempo, essa transformação está sendo concluída em larga escala, mesmo que não completamente ainda. Quanto à situação alemã, essa reforma causou efeitos bastante radicais, especialmente para as ciências humanas e sociais, que foram obrigadas a dividir seu tradicional currículo bem-sucedido do mestrado de dez semestres em duas fases separadas, um modo sempre já válido, em grande parte, nas ciências naturais e técnicas. Alguns currículos, como na área das licenciaturas, do direito e da medicina, até hoje, vêm se opondo, com certo sucesso, a essa reforma; porém, é apenas uma questão de tempo até que se efetuem, também nessas áreas, as respectivas transformações (em alguns estados alemães, já se introduziu o Master of Education).

Ainda que essa divisão bipolar do currículo tenha levado a sérios problemas em algumas disciplinas - pois processos de formação de prazo maior, permitidos no caso do antigo mestrado, precisavam ser transferidos em processos de prazo mais curto -, o seu entrave principal está no fato de os currículos de Bachelor serem considerados, por definição, de "qualificação profissional"; algo que significa para as disciplinas das ciências humanas e sociais um mero engano de etiqueta. De repente, currículos de formação clássica viram-se transformados, assim, sob nome novo, em currículos de instrução profissional que, entretanto, não encontram um mercado de trabalho específico para as disciplinas. Na verdade, isso significa, para as ciências humanas e sociais, redução a uma formação de bitola estreita, cuja instrução profissional não encontra qualquer perspectiva profissional e para a qual também faltam - por causa do tempo escasso - oportunidades de especialização. Por isso, muitos dos alunos acrescentam à sua formação o Estudo de Master, mesmo sem projetar seu próprio futuro numa carreira acadêmica.

Quanto à terceira e à quarta demandas, fala-se da mobilidade como objetivo, no intuito de promover a exploração plena do espaço europeu das escolas superiores por parte dos estudantes. Originalmente, a ideia básica, nesse contexto, era mesmo revolucionária, na medida em que ela visava à abolição de um currículo hierárquico. $\mathrm{O}$ estudo - eis a ideia - deveria consistir apenas de módulos tematicamente definidos, representando uma extensão específica do tempo de trabalho, ex- 
presso por pontos de crédito (ECTS). Conforme a tendência de individualização nas sociedades pós-industrializadas - analisada de modo impressionante por Ulrich Beck (1986) já nos anos 1980 -, viveu-se o sonho de um estudante que migra, como "nômade de formação", pelo espaço europeu das escolas superiores (universidades), compondo seus estudos por módulos, individualmente escolhidos, de diversas universidades e revelando, assim, um perfil inteiramente individual. No entanto, essa perfeita revolução pós-industrial de formação fracassou radicalmente, com exceção da implementação do ECTS e da estrutura modular dos estudos por fora. Com efeito, as comissões de planejamento curricular, na sua maioria um teatro leigo de professores mal informados, transferiram apenas os antigos currículos na forma nova. Em consequência disso, currículos - frequentemente monstros sobrecarregados por exames - praticamente impediam o aluno de terminar o estudo dentro do prazo regular previsto. Além disso, tanto a alta pressão de ter que passar por inúmeros exames quanto os currículos muito específicos impediram, em ampla escala, a mobilidade dos estudantes. Somente através da reformulação dos currículos, realizada ao longo dos últimos anos, a situação viu-se melhorada, mantendo-se, no entanto, a antiga estrutura curricular.

Ora, a ampla revolução pós-industrial na área das escolas superiores não aconteceu, fato que não significa, porém, que se fechasse um trinco contra sua economização. Ao contrário, tanto a estrutura modular por fora quanto, sobretudo, o sistema ECTS levaram à contabilização de processos de formação que - se dispuséssemos de mais tempo - poderiam ser compreendidos muito bem mediante a análise do valor, feita por Marx. "Créditos" vêm se transformando no "dinheiro do espírito", na medida em que eles deveriam expressar o tempo de seu (do espírito) trabalho: com isso, cada currículo é contado à base de uma semana igual a 40 horas de trabalho do espírito, contagem que precisa se espelhar detalhadamente no número dos créditos a serem alcançados. Que isso consiste num absurdo completo é sabido por todos os envolvidos, isto é, pelos planejadores dos currículos, pelos professores e pelos estudantes, o mais tardar desde as experiências práticas. Todavia, o problema aí não está, em primeira linha, na impossibilidade de contabilizar os processos de formação, senão muito mais no fato de tal estrutura impedir, antes, qualquer processo de formação, de modo que, por exemplo, o tempo necessário para terminar a leitura de uma obra - tomemos a Crítica da razão pura, de Kant - não é previsto no orçamento temporal de tal currículo (quem, apesar disso, completa a leitura, ver-se-ia mesmo culpado pelo tempo prolongado de seu estudo, para o qual perderia o apoio financeiro). Em consequência disso, os professores têm a responsabilidade de reduzir, consideravelmente, as exigências e os conteúdos de formação e adequá-los ao tempo disponível, impedindo, assim, na maioria dos casos, qual- 
quer aprofundamento dos conteúdos e problemas. Por parte dos estudantes, a isso corresponde uma crescente orientação pela efetividade, cada vez menos dirigida a necessidades objetivas e mais orientada às exigências formais - no sentido de quando o tempo faltar, basta substituir o capítulo sobre a Crítica da razão pura por qualquer introdução à filosofia de Kant. Ou seja, deixa-se de lado a leitura dos clássicos e concentra-se a instrução cada vez mais no estudo de manuais e comentadores dos autores.

Com as duas últimas demandas da Declaração de Bolonha, tem-se, finalmente, mais um instrumento das sociedades avançadas de prestação de serviços no campo das escolas superiores: a garantia de qualidade e o retículo de critérios de qualidade a ela vinculado. Não é apenas cada currículo do Bachelor e do Master que tem de passar a cada cinco anos por um processo exigente de (re)credenciamento, realizado, a custos muito altos, por agências especiais de credenciamento. A garantia de qualidade estende-se por todas as esferas das escolas superiores, desde as entrevistas que abrangem todas as escolas superiores, passando-se por entrevistas dos alunos formados, até as avaliações normatizadas dos cursos específicos, que têm de ser realizadas, periodicamente, por cada faculdade.

Devido à maneira referida e à amplitude das medidas, a intenção, em princípio razoável, de expor a qualidade dos estudos a uma reflexão e a um controle repetidos, torna-se, no entanto, um empreendimento cada vez mais vazio, pois normatizado independentemente dos limites disciplinares; aí, as despesas excedem, em muito, os ganhos concretos enquanto melhorias das condições dos estudos. Há, entretanto, um efeito à contramão dessas medidas: critérios de avaliação normatizados levam, passo a passo, à normatização do que está sendo avaliado, pois uma avaliação positiva, um (re)credenciamento bem-sucedido etc. só se tornam possíveis se os operadores (professores, institutos) se adaptarem às exigências dos critérios normativos. Nesse retículo, caminhos inovadores e espaços para configurações individuais não são previstos - numa tal avaliação do ensino, uma preleção no estilo de Hegel fracassaria de modo tão radical como, de outra parte, uma preleção no estilo de Paul Feyerabend. Se levarmos em conta que, hoje, essas avaliações do ensino fazem parte de quase cada concurso para uma vaga de professor, os espaços criativos neutralizam-se em virtude da troca crescente das gerações.

O que foi afirmado até aqui se aplica não apenas para o ensino, senão e de modo igual à pesquisa, pois esta hoje se vê, da mesma forma, dominada amplamente pelo cálculo econômico. Ao decorrer das, assim chamadas, reformas, implementou-se, igualmente, uma reforma do salário dos professores que, desde 2005, consiste num salário básico reduzido, que pode ganhar aumentos dependendo da eficiência e da produtividade do trabalho realizado. É verdade que esses acrésci- 
mos podem ser alcançados, também, graças ao trabalho destacado no ensino, mas estes são concedidos, antes de tudo, à base da produção particular na pesquisa e da aquisição de recursos externos. Em geral, a aquisição de tais recursos (isto é, de fomento, concedidos por órgãos de incentivo à pesquisa) tornou-se um tema central na paisagem alemã das escolas superiores, visto que estas conseguem aumentar com esses respaldos seu orçamento financeiro escasso e seus recursos humanos. Destarte, os acordos firmados entre a direção e os professores sempre vêm sendo vinculados a uma perspectiva de aquisição de recursos externos, um fato que leva à situação segundo a qual, dito de modo um pouco exagerado, a quantia da literatura de pedidos de financiamento, hoje, ultrapassa o tamanho das literaturas de pesquisa que podem ser tomadas a sério.

Uma das consequências desse desenvolvimento é a tendência de escolher e pesquisar apenas os temas com expectativa de financiamento à base de recursos externos. Aí, não existe critério objetivo algum para legitimar essa expectativa; na sua maioria, ela é determinada pelo olhar subjetivo do requerente e pelo que lhe parece estar en vogue - como que em obediência antecipada diante dos peritos. Tendo em vista que essa impressão subjetiva, geralmente, depende da percepção consciente ou também inconsciente de tendências presentes em debates contemporâneos dos periódicos científicos ou das demais mídias, chega-se, por consequência, à situação de negligenciar cada vez mais os temas aparentemente periféricos no leque atual da pesquisa. Em resumo, isso leva a um estreitamento e a uma homogeneização dos temas de pesquisa, que, a longo prazo, criarão efeitos problemáticos, pois a pesquisa verdadeiramente inovadora, via de regra, não segue as trilhas estreitas da ciência normal, ou seja, não se encontra dentro no marco do puzzle solving no sentido de Kuhn (1976, p. 50), senão segue, segundo a história das ciências, muitas vezes, desvios aparentes.

Consequências desses desenvolvimentos são, para indicar apenas algumas, as seguintes: a) publicações orientadas pela sua função, mais interessadas na quantidade dos títulos do que na qualidade do conteúdo objetivo (a produção restrita, por exemplo, de Espinosa pouco impressionaria uma banca moderna que decide sobre uma vaga de professor); b) uma prática de nomeação como que de família, pela qual se valoriza cada vez menos a diversidade objetiva em favor dos vínculos temáticos e institucionais; e c) finalmente, o estreitamento dos conteúdos de ensino e de formação em geral, na medida em que a homogeneização da paisagem das pesquisas leva cada vez mais à redução da variedade dos conteúdos do ensino.

Gostaria de fazer aqui um breve corte. Todos os desenvolvimentos até aí descritos, deduzidos das seis demandas básicas da Declaração de Bolonha, são dirigidos para a unificação, a comparabilidade e a contabilização, visando, portanto (no 
sentido econômico), a unificar e a tornar operacional o valor da formação e do saber. A descrição "econômico", porém, aqui não caberia nem um pouco, se, ao mesmo tempo, não nascesse dessas estruturas uma tendência diametralmente oposta: a tendência em favor da diferenciação. Assim, como o sonho americano - em termos econômicos - de uma igualdade principal (de chances) representava e representa uma quimera bem-intencionada, a fim de desviar o olhar das desigualdades existentes e de estigmatizá-las, no sentido positivo ou negativo, como criadas por culpa própria, as tendências descritas da unificação do ensino servem apenas de base para estabelecer uma diferenciação mais efetiva na paisagem europeia de formação.

Ora, enquanto na França e na Inglaterra a concorrência entre as escolas superiores tem tradição longa, ela é desconhecida na tradicional paisagem alemã das escolas superiores. É verdade que surgiram sempre de novo determinados institutos disciplinares que alcançaram, devido a pesquisadores destacados, uma fama considerável; no entanto, essa situação não era nem um pouco comparável, por exemplo, com a concentração francesa da formação universitária em Paris ou da inglesa em Oxford ou Cambridge. Somente nos anos 1990, essa situação mudou lentamente na Alemanha, desde que periódicos políticos e econômicos, como Spiegel, Focus, Handelsblatt etc., de repente, elaboraram "rankings", à base de questionáveis settings metódicos, mediante os quais as universidades se viam comparadas segundo critérios aparentemente uniformes e incluídas em listas hierárquicas.

A implementação dos critérios de comparação em termos da política educativa foi garantida - como acima descrito - pelo Processo de Bolonha. Uma implementação igual à dos "rankings" demorou até 2005/6, quando os recursos estatais, provindos da venda das licenças das redes móveis de comunicação (UMTS - licenças), providenciavam a base financeira para a assim chamada "Iniciativa de excelência dos governos federal e estaduais para o fomento das ciências e da pesquisa nas escolas superiores alemãs". Ainda que a Deutsche Forschungsgemeinschft (DFG), que corresponde ao Conselho Nacional de Desenvolvimento Científico e Tecnológico $(\mathrm{CNPq})$ brasileiro, já tivesse preparado, embora extraoficialmente, uma diferenciação da paisagem de pesquisa mediante a concentração da concessão de recursos em instituições específicas, essa política levou, oficialmente, a partir de 2005/6, e por meio dessa Iniciativa de excelência, a uma diferenciação duradoura, desde que recursos de pesquisa bastante amplos foram concentrados em poucos lugares, que, por sua vez, puderam se apoderar do bonito título de "universidade de elite" - como já dito, uma denominação tradicionalmente estranha à paisagem universitária alemã. 
O objetivo explícito desse programa de excelência era, e ainda é, a tentativa de reconduzir a pesquisa alemã para o topo mundial, ou seja, ser mais bem colocada no "ranking" internacional; uma tentativa que parece grotesca, devido ao simples fato de o orçamento anual de toda Iniciativa de excelência (que é dividido entre dez universidades de elite e, no mínimo, mais dez) corresponder, aproximadamente, aos recursos anuais da Universidade de Harvard. O futuro mostrará se esse objetivo se realizará em algumas áreas singulares - é, no entanto, um fato que a paisagem universitária alemã se alterou fundamentalmente e continua se alterando.

Se seguirmos a análise de Michael Hartmann, essa alteração levará a uma cisão profunda. Nas suas palavras:

Passo a passo, a concentração dos recursos financeiros para a pesquisa e a relação modificada entre pesquisa e ensino levarão a uma cisão profunda das aproximadamente 100 universidades existentes, entre um pequeno grupo de universidades dirigidas para a pesquisa e um grupo muito maior de Escolas Superiores, dirigidas para a instrução profissional. Ao primeiro grupo pertencerão os vencedores da Iniciativa de Excelência, ao passo que ao segundo pertencerão os perdedores que, de um ano para o outro, reforçarão uma liga junto às Escolas Superiores de Ciências Aplicadas (2010, p. 381).

Os círculos diabólicos que promoverão esse desenvolvimento dizem respeito, antes de tudo, à concentração dos recursos financeiros em determinadas universidades, dando-lhes condições cada vez melhores - recursos que são vedados às escolas superiores perdedoras. Essa espiral diferenciadora não requer explicação alguma. Além disso, pesquisadores de destaque vêm sendo atraídos pelas universidades de elite mediante a redução de sua carga horária de ensino, um fato que minará a unidade tradicional de pesquisa e ensino. Em troca disso, a ideia de contratar para o ensino, futuramente, cada vez mais professores com carga horária consideravelmente aumentada é uma consequência lógica, já preparada mediante a implementação abrangente de vagas de alta carga horária em nível médio (os assim chamados "professores para tarefas específicas", com 14 ou mais aulas/horas semanais). Que essa tendência também encaminhará uma espiral diferenciadora explica-se, de mesmo modo, por si só.

Após essa apresentação das mudanças no campo alemão (e europeu) da formação superior, quero abordar, rapidamente, alguns outros setores de formação, a fim de tornar claro que essas mudanças representam uma tendência geral da adaptação da formação (Bildung) a estruturas econômicas - o que foi, de fato, minha tese inicial. Começo com a formação escolar: também nela se encontram processos de 
uniformização de mãos dadas com tendências de diferenciação, de modo que essa junção resulta muito mais da lógica econômica (inerente a ambas as tendências). No que se refere à uniformização, verificam-se a quase abrangente redução dos anos escolares do segundo grau de nove para oito anos e a implementação do centralizado exame final do liceu, com questionários uniformizados. Produtos dessas medidas unificadoras são, em primeiro lugar, alunos completamente sobrecarregados que conseguem vencer as matérias (enormemente condensadas graças à redução insuficiente dos currículos) somente à base do trabalho aos fins de semana e da redução das atividades de lazer, e, em segundo lugar, um modo de aprendizagem dos alunos, orientado pela eficiência, que concentra a atenção, única e exclusivamente, naquelas matérias que são relevantes para os exames centralizados.

Quanto ao fundo dessas medidas, é possível dizer que ambas representam reações mais ou menos diretas ao assim chamado "choque de Pisa", vivido pela Alemanha há dez anos, devido aos resultados ruins dessa comparação internacional dos aproveitamentos escolares. O que opera como pano de fundo, em todas essas transformações na esfera educacional, é um contexto claramente econômico, já que o estudo de Pisa, realizado nos anos 2000 e 2003 em 32 países, foi e continua sendo um projeto da Organização para a Cooperação e Desenvolvimento Econômico, isto é, da "Organisation for Economic Cooperation and Development" (OECD) de seus estados-membros (o último estudo aconteceu em 2009). Assim consta no prefácio da "concepção geral":

O estudo internacional PISA (Programme for International Student Assessment) sobre o aproveitamento escolar, promovido pela OECD, expressa o autocomprometimento novo dos Estados-membros da OECD de alcançar uma imagem da produtividade de seus sistemas de formação, mediante a medição do aproveitamento dos alunos à base de uma comum concepção internacional (Deutsches Pisa - Konsortium, 2000, p. 5).

No entanto, o cerne dessa concepção geral é um entendimento novo da formação (Bildung) concebido pelo conceito "literacy" (MESSNER, 2010). Foram contempladas apenas três áreas de formação ou "literacy", a saber: competência de leitura (reading literacy), formação básica na matemática (mathematical literacy) e formação básica nas ciências naturais (scientific literacy). No fundo dessa concepção, está uma orientação pragmática do conceito de formação, o que fica óbvio pela definição da competência de leitura: "Entender textos escritos, utilizá-los e refletir sobre eles, no intuito de alcançar objetivos próprios, desenvolver os próprios conhecimento e potencial, e participar na vida social" (BAUMERT, 2001, p. 23). Num primeiro olhar, essa definição soa completamente não problemática, cada um podendo aceitá-la em princípio. Porém, ela contém uma determinação da competência de leitura que não pode ser subestimada e que deveria ser resumida pelos três aspectos seguintes: 
$\left.1^{\circ}\right)$ Ler, segundo essa definição, é considerado um ato meramente cognitivo, no qual os aspectos estéticos e emocionais ficam desrespeitados em ampla escala, algo apontado, por exemplo, por Rudolf Messner (2010).

$2^{\text {o }}$ Ler, segundo essa definição, vem sendo completamente desvinculado da palavra falada e escrita - uma interação acontece apenas entre leitor e texto, algo apontado também por Dietrich Benner (2002).

$3^{\text {o }}$ Ler, segundo essa definição, é considerado essencialmente um meio para realizar objetivos específicos, como é típico para textos que tratam de uma determinada matéria; ele não é considerado, em primeira linha, um fim em si mesmo, tal como acontece com textos mais estético-poéticos. ${ }^{4}$

Não quero abordar aqui os detalhes das críticas referentes a essa concepção; no entanto, é necessário vislumbrar que esse conceito de formação se enquadra muito bem no marco econômico, contexto no qual ele foi elaborado. Esse fato, entretanto, não significa uma crítica do procedimento desse estudo, senão do marco econômico ao qual o estudo foi adaptado.

Mais interessante ainda é que a tendência de comparação dos aproveitamentos, oriunda do processo da diferenciação universitária e realizada em analogia aos "rankings" das universidades, já se estende, hoje em dia, às escolas básicas, desde que, em 2011, uma primeira comparação do aproveitamento em 1.300 escolas básicas foi realizada no território alemão. Não se espera mais muito tempo para a extensão dessa tendência até as pré-escolas e aos jardins de infância, pois já existem concepções uniformes da formação e educação que compreendem o período do nascimento à passagem para o liceu. O Estado de Hessen, por exemplo, editou, em 2007, um "Plano de formação e educação para crianças de 0 a 10 anos", com o título expressivo de "Formação desde o início". ${ }^{5}$ Trata-se de algo que se dá, como que naturalmente, de mãos dadas com programas de formação para os jardins de infância, dirigidos e concentrados nas matérias principais do inglês e da matemática, já dirigidas para a escola e o mercado de trabalho. Em resumo: com essas medidas, as reivindicações de um mercado de trabalho globalizado já se vêm irradiando para o desenvolvimento da primeira infância, um fato que desemboca numa concepção unificada de formação, desde o nascimento até o exame final na universidade, mas, o que é preocupante e motivo de reflexão entre nós, numa direção única e cada vez mais mercadológica.

\section{III}

Contento-me com esse breve excurso referente às demais instituições de formação para chegar a uma avaliação final das tendências expostas. Essa avaliação se orienta por um conceito de formação (Bildung) que vê, no processo formativo uni- 
versal do potencial humano, um fim em si mesmo, opondo-se, consequentemente, a uma orientação por critérios de eficiência segundo objetivos específicos (antes de tudo econômicos), inscritos aos currículos de instrução profissional. Esse conceito clássico de formação entra, mediatizado por Rousseau, Kant, Schleiermacher e outros, também, na ideia da universidade, defendida por Humboldt. Nunca é demais lembrar que tal ideia - ainda que apenas em princípio - expressou, durante muito tempo, o fundo firme da paisagem alemã de formação, a qual foi sendo descaracterizada, até seu desfiguramento, ao longo desses últimos quinze anos. Nesse nosso contexto, quero lembrar três aspectos da ideia clássica de formação.

O primeiro aspecto aponta para a autonomia da universidade, ou seja, para sua liberdade frente à influência de reivindicações estatais. O ponto de partida da reivindicação pela autonomia está na contrariedade dos interesses entre Estado e Ciências, já explicitamente formulada por Schleiermacher, no que se refere ao saber. Assim afirma o autor:

O Estado é, naturalmente, convencido de e preso apenas pela utilidade imediata dos conhecimentos. Ele tenta favorecer o extenso conhecimento de fatos, fenômenos e sucessos de todo tipo e, se preocupado com as instituições científicas, orientá-las, sobretudo, nessa direção. Aqueles, porém, que se unem voluntariamente a favor das Ciências, preocupam-se com algo bem diferente da mera massa de conhecimentos. O que os une é a consciência da unidade necessária de todo saber, das leis e condições de seu surgimento, da forma e do caráter que fazem de cada percepção, de cada pensamento um saber verdadeiro $\left(1984\right.$, p. 88). ${ }^{6}$

Se aplicada essa contrariedade à situação moderna, incluindo-se no termo "Estado" também demandas econômicas, parece verificar-se o que Schleiermacher pouco adiante profetiza no seu texto: "Quanto mais os cientificamente formados veem-se concatenados com o Estado, de tal modo que o científico se vê neles dominado pelo político [hoje, diríamos também: pelo econômico - D.S.] sem chegar à plena consciência, tanto mais cedo eles adaptar-se-ão às intervenções do Estado" (1984, p. 90). Quanto mais a universidade se aproxima estruturalmente de uma empresa econômica, tanto mais seus membros assumirão, de forma progressiva, a consciência empresarial, supondo-se que não reflitam permanentemente essas estruturas. É verdade que as formas de identificação estrutural se implementam de modo oculto; no entanto, na ampla atividade que caracteriza cada vez mais a universidade como empresa, diminuindo o espaço para a reflexão, aquela identificação acontece num processo aparentemente contínuo.

De outra parte, Humboldt ainda esperava de um Estado que "não precisaria reivindicar" das universidades "nada diretamente referido a ele; ao contrário, ele deveria ter a convicção intrínseca de que, se as universidades alcançassem seu próprio objetivo final, elas cumpririam também seus fins de um modo muito mais elevado" (1964, p. 260). O ideal de autonomia segundo o qual o Estado, confiante quanto ao objetivo comum de criar seres humanos universalmente formados e 
somente por isso maiores ${ }^{7}$, deixa as universidades trabalharem livremente, sem intrometer-se nos seus assuntos, inverteu-se no que o Estado e a economia vêm confiando como que, naturalmente, na adaptação contínua das instituições aos objetivos imediatamente fixados na utilidade e na rentabilidade econômica. Infelizmente, a última esperança é hoje muito mais bem fundamentada do que a primeira.

O segundo aspecto, ao qual quero apontar com referência ao conceito clássico de formação, tem a ver com uma formação universal. De acordo com Humboldt, esta se inicia já na escola, marcando sua tarefa principal (também como preparação para a entrada na universidade). Segundo esse autor, a escola precisa:

[...] pensar apenas na formação harmônica de todos os potenciais de seus educandos; apenas exercer sua força em número menor possível de objetos e por todos os seus lados; e implantar todos os conhecimentos na sua alma de tal modo que a compreensão, o saber e a produção espiritual ganhem sua atração não graças a circunstâncias externas, senão através de sua precisão, harmonia e beleza internas (1964, p. 261).

A situação atual nas escolas alemãs está longe, até muito longe (apesar da existência de alguns poucos projetos de reforma) dessa ideia de formação escolar que visa a acordar nos educandos um interesse intrínseco pelas matérias de formação, reduzindo-as a um mínimo, mas as experimentando em toda sua amplitude. Ao contrário, são os interesses extrínsecos (a orientação pelas exigências do exame, pela massa de matéria a ser trabalhada, pela eficiência metódica de aprendizagem etc.) que constam como fatores dominantes, estampando profundamente a mentalidade educativa dos alunos.

É evidente, após o Processo de Bolonha, que a estruturação maior dos currículos e a importância crescente dos resultados dos exames nas escolas superiores fecham bem com a referida mentalidade extrínseca dos alunos, pois, assim, a mentalidade escolar se estende, sem interrupção, à universidade. Porém, mais um momento da universalidade ganha importância para as escolas superiores: a unidade do saber, já apontada por Schleiermacher, com a qual as ciências e a pesquisa se sentem comprometidas. O erudito clássico (Der klassische Gelehrte), que é capaz de vincular seu objeto específico de pesquisa ao horizonte geral de formação, buscando permanentemente tais conexões, cedeu lugar ao cientista - especialista interessado na carreira, cujas chances no mercado universitário de trabalho crescem com a orientação estrita às reivindicações específicas do próprio mercado. Mesmo nos lugares onde se realiza explicitamente uma pesquisa interdisciplinar, esta, muitas vezes, parece ingenuamente desligada do horizonte mais amplo do conteúdo da formação.

A busca por uma unidade do saber, por contextos superiores acontece cada vez menos, vendo-se declarada, precipitadamente, como algo não realizável e ultrapas- 
sado com a referência à confusão causada pela massa de fatos e conhecimentos. Assim, formação e pesquisa universitárias igualam-se cada vez mais àquela pasta de registros, da qual Adorno e Horkheimer falam no capítulo sobre a indústria cultural, na Dialética do esclarecimento: "A assim chamada ideia abrangente é uma pasta de registros que cria ordem, mas não concatenação" (1988, p. 134).

Finalmente, quero apontar - como terceiro aspecto - uma constelação, na qual a interligação entre formação e economia salta aos olhos - refiro-me ao fato de a riqueza e as chances de formação andarem juntas, isto é, de modo proporcional, e, analogamente, pobreza e chances de formação realizarem-se desproporcionalmente. Embora tenha sido claramente revelada mediante diversos estudos (e.o. Pisa), sobretudo na Alemanha, essa interdependência marca um fenômeno geral de nosso modelo econômico atual e está no cerne de qualquer reforma de formação que o segue. A segregação social estende-se diretamente à diferenciação da formação, e vice-versa, criando uma espiral não promissora quanto ao futuro da democracia.

Todavia, não quero finalizar minha avaliação com pessimismo total, pois não somos os únicos que visam a refletir criticamente esses problemas, explorando, onde possível, as lacunas e os espaços livres, para providenciar ainda um lugar para a ideia clássica de uma formação autônoma geral - não por última também nesse nosso encontro.

\section{The idea of education (university) and its economic deformation: an end chant}

\section{Abstract}

The article aims to do a brief assessment of the German university situation, with reference to the effects produced by the introduction of the measures and requirements arising from the Bologna Declaration. Firstly exposes and analyzes each of the six main measures of the Declaration. Second$l y$, indicates the visible consequences that it causes, the pedagogical point of view and intellectual training of students, devoting itself also to examine, briefly, its effects on primary and secondary education. Finally, in order to make a critical assessment of the situation, uses the classic sense of the German formation (Bildung), highlighting three of its many aspects. In the discussion is the effort to undertake a critique of the global trend, and especially German, of commercialization of education.

Keywords: Autonomy. Bildung. Commercialization of Education. Freedom. Higher Education. 


\section{Notas}

1 Título original: "Die idee der (universitären) Bildung und ihre ökonomische deformation". Conferência proferida no I Colóquio Internacional sobre Sociedades Complexas, realizado no Programa de Pós-Graduação em Educação (PPGEDU), da Universidade de Passo Fundo, nos dias 14 e 15 de março de 2013. Tradução e revisão: Hans-Georg Flickinger e Claudio A. Dalbosco.

2 Sorbonne Joint Declaration. Joint declaration on harmonisation of the arquitecture of the European higher education system, Paris, May 25, 1998.

3 Der Europäische Hochschulraum. Gemeinsame Erklärung der Europäischen Bildungsminister (O espaço europeu das escolas superiores. Declaração coletiva dos ministros de cultura europeus), 19. Juni 1999, Bologna.

4 Não deveria deixar de mencionar que a concepção de "literacy" marca, por exemplo, na área da "scientific literacy", também, um avanço considerável diante do conceito de formação, presente na Alemanha no campo das ciências naturais. À base dessa concepção do "context of discovery", por assim dizer, fica mais central do que é exigido pela didática da matemática.

5 Bildung von Anfang an. Bildungs - und Erziehungsplan für Kinder von 0 bis 10 Jahren in Hessen (Formação desde o início. Plano de formação e educação para crianças de 0 a 10 anos de idade em Hessen), ed. pelo Ministério de Cultura e de Assuntos Sociais do Estado de Hessen, Wiesbaden 2007, (4. ed. 2012).

6 Antes de Schleiermacher, foi Schelling quem já apontou, com ênfase, à ideia da "unidade do saber"; comp. F.W.J.Schelling, Vorlesungen über die Methode des akademischen Studiums (Preleções sobre o método do estudo acadêmico) (1803), em: Sämtliche Werke (Obras Completas), vol. V, Stuttgart 1859, p. 207-352 (sobretudo a $1^{\mathfrak{a}}$ preleção).

7 Humboldt insere-se, aqui, nitidamente, na melhor tradição moderna de pensamento sobre a natureza e 0 papel do Estado, que por meio da educação constitui a instância formadora da vontade moral dos indivíduos. Sobre isso, ver, por exemplo, o Emílio de Rousseau. [N. T.]

\section{Referências}

BECK, U Risikogesellschaft. Auf dem Weg in eine andere Moderne. Frankfurt: Suhrkamp, 1986. [Trad. port.: Sociedade de Risco: rumo a uma outra modernidade. São Paulo: Editora 34, 2011]. BENNER, D. Die Struktur der Allgemeinbildung im Kerncurriculum moderner Bildungssysteme. Ein Vorschlag zur bildungstheoretischen Rahmung von Pisa (A estrutura da formação geral no currículo central de sistemas modernos de formação. Uma proposta referente ao marco teórico de formação do PISA), em: Zeitschrift für Pädagogik, Jg.48, 2002/.

DEUTSCHES PISA-KONSORTIUM (Hrgs). Schülerleistungen im internationalen Vergleich. Eine neue Rahmenkonzeption für die Erfassung von Wissen und Fähigkeiten (Aproveitamento de alunos na comparação internacional. Uma concepção nova do marco para o registro de conhecimentos e de habilidades). Berlin, 2000.

HARTMANN, M. Die Exzellenzinitiative und ihre Folgen (A Iniciativa de Excelência e suas consequências) em: Leviathan, 38/2010.

HORKHEIMER, M.; ADORNO, T. W. Dialektik der Aufklärung. Philosophische Fragmente. Frankfurt a. M.: Suhrkamp, 1988. [Trad. port.: Dialética do Esclarecimento. Fragmentos filosóficos. Rio de Janeiro: Zahar, 1985.

HUMBOLDT, W. V. Über die innere und äußere Organisation der höheren wissenschaftlichen. Anstalten in Berlin (Sobre a organização interna e externa das instituições científicas superiores em Berlin) (1810), em: idem, Werke in fünf Bänden (Obra em 5 volumes). vol. IV, Stuttgart: Reclam, 1964.

KUHN, T. S. Die Struktur wissenschaftlicher Revolutionen. Frankfurt a. M: Suhrkamp. 1976. [Trad. port.: A estrutura das revoluções científicas. São Paulo: Perspectiva, 1990].

MESSNER, R. Das Bildungskonzept von PISA als Teil einer globalen gesellschaftlichen Neuorientierung (A concepção de formação do PISA como parte de uma orientação social nova em nível global), in: Erziehung und Unterricht, H.7/8, 2000.

SCHLEIERMACHER, F. Gelegentliche Gedanken über Universitäten im deutschen Sinn (Ideias casuais sobre universidades no sentido alemão) (1808), em: Pädagogische Schriften 2, Frankfurt am Main: Suhrkamp, 1984. 